\title{
MODAL ANALYSIS OF GEARBOX TRANSMISSION SYSTEM IN BUCKET WHEEL EXCAVATOR
}

\author{
Maha Karray, Nabih Feki, Mohamed T. Khabou, Fakher Chaari, Mohamed Haddar \\ Laboratory of mechanics, Modelling and Production, National school of Engineers of Sfax, Sfax, Tunisia \\ e-mail: fakher.chaari@gmail.com
}

\begin{abstract}
Planetary gears are widely used in modern machines as ones of the most effective forms of power transmission. In this paper, a special configuration of a gearbox composed of one stage spiral bevel gear and a two stage helical planetary gear used in a bucket wheel excavator gearbox is presented to investigate its modal properties. A lumped-parameter model is formulated to obtain equations of motion and the eigenvalue problem is solved. The modes are presented in low-frequency and high-frequency bands. Distributions of modal kinetic and strain energies are studied.

Keywords: spiral bevel gear, helical planetary gear, bucket wheel excavator, modal properties
\end{abstract}

\section{Introduction}

Gear transmissions such as bevel and planetary gears are widely used in transmissions of wind turbines, agricultural machinery, mining machines such as excavators and transportation such as helicopters. Spiral bevel gears BG coupled in two stages helical planetary gears can be found in gearboxes of bucket wheel excavators. The first step to investigate the dynamic behavior of such systems is the determination of natural frequencies and mode shapes.

Many research works has been done on common parallel axis geared rotor systems dynamics, see e.g. Ozguven and Houser (1988a,b), Blankenship and Singh (1995), Velex and Maatar (1996) however few research works were dedicated to bevel gears dynamics. The existing models are mostly similar to those of parallel axis gears. Gosselin et al. (1995) proposed a general formula and applied it to analyze the load distribution and transmission error in spiral bevel gear pairs and hypoid gear pairs. Karray et al. (2013) investigated the dynamic behavior of a single stage bevel gear in the presence of local damage. Choy et al. (1991) presented vibration signature analysis for multi-stage gear transmissions which combined gear mesh dynamics and structural modal analysis in the study of transmission vibrations.

For planetary gears, Kahraman (1994b) provided expressions for natural frequencies by using a rotational lumped-parameter model. Lin and Parker (1999a, 2000) showed that two-dimensional, spur planetary gears with equally spaced and diametrically opposed planets possess well-defined modal properties. Wu and Parker (2008) proved the modal properties of spur planetary gears having elastically deformable ring gears. These vibration mode characteristics are crucial in vibration suppression strategies using mesh phasing (Seager, 1975; Lin and Parker, 2004) and eigensensitivity analysis (Lin and Parker, 1999b), Guo and Parker (2010) of planetary gears. Although the vibration modes of two-dimensional planetary gears have been studied, few studies were dedicated to those of helical planetary gears with three-dimensional motion. Habib et al. (2005) determined critical frequencies for helical planetary gears and examined their sensitivity to the helix angle. Eritenel and Parker (2009) examined three-dimensional motion of helical gears and shafts. 
Researches on modal characteristics of multistage planetary gears are rare. Sun et al. (2014) analyzed the natural frequency and coupled mode characteristics in a multi-stage planetary gear and distinguished the dominant vibration stage by a criterion. Hammami et al. (2015) discussed the modal properties of a special configuration of two stage planetary gears mounted back-to-back. Zhang et al. (2016) attempted to establish a translational-rotational coupled dynamic model of a two-stage closed-form planetary gear set to predict natural frequencies and vibration modes.

This paper discusses the modal properties of a special configuration of a gearbox composed of one stage spiral bevel gear and two stage helical planetary gear used in bucket wheel excavators. A lumped-parameter model is formulated to obtain the equations of motion.

\section{Dynamic model}

Figure 1 shows a general view of a bucket wheel excavator. The kinematic scheme of its gearbox transmission system is presented in Fig. 2. It is composed of a spiral bevel gear as the input and two stages planetary gear.
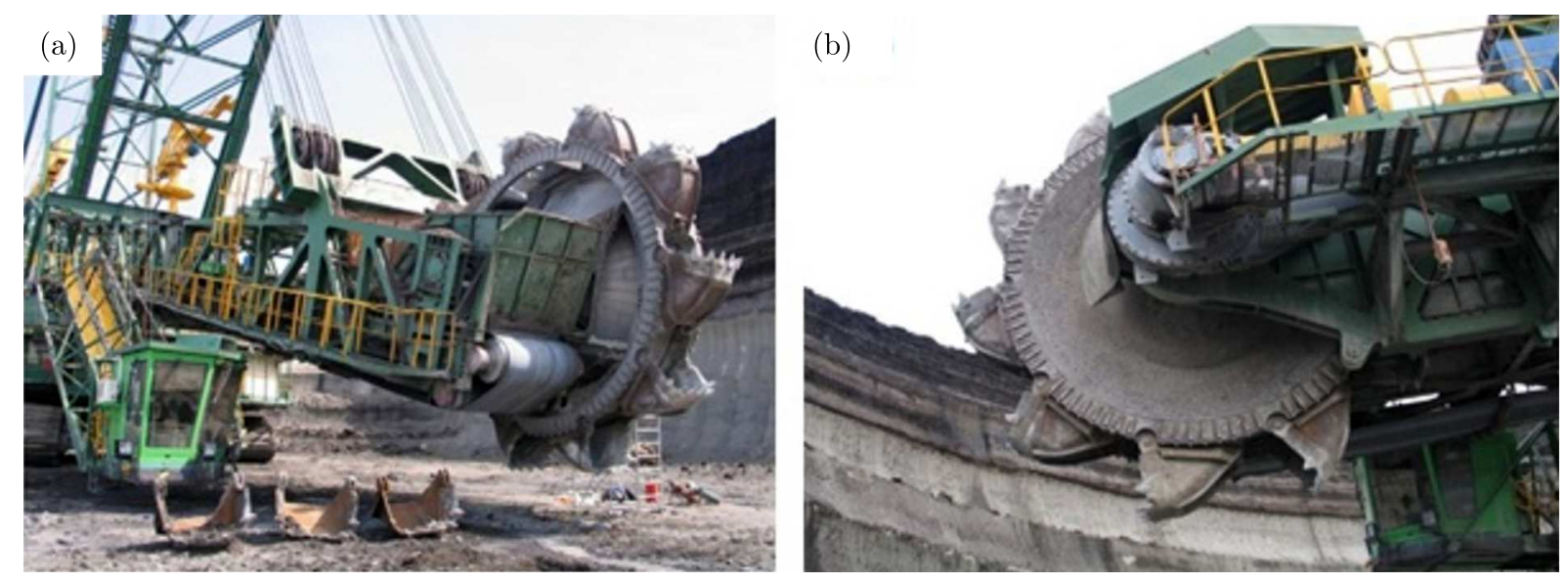

Fig. 1. View of the bucket wheel excavator: (a) from the side of winning-receiving belt and (b) from the side of the transmission system (Rusinski et al., 2010)

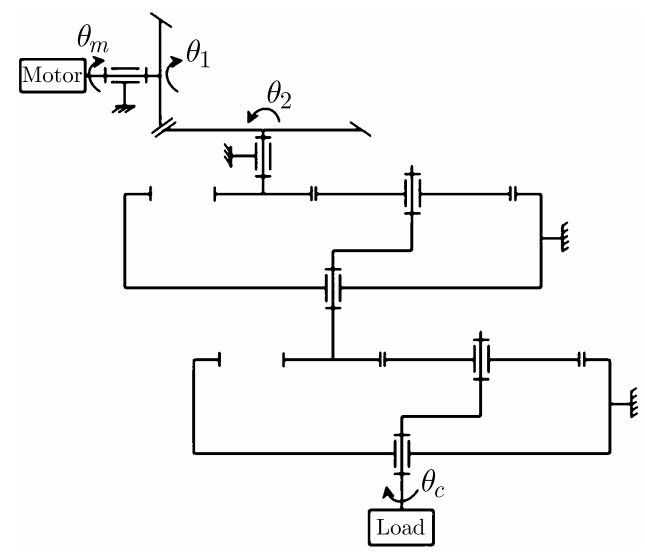

Fig. 2. Kinematic scheme of the gearbox transmission system 


\section{Model and equation of motion}

The model of the transmission is presented in Fig. 3.

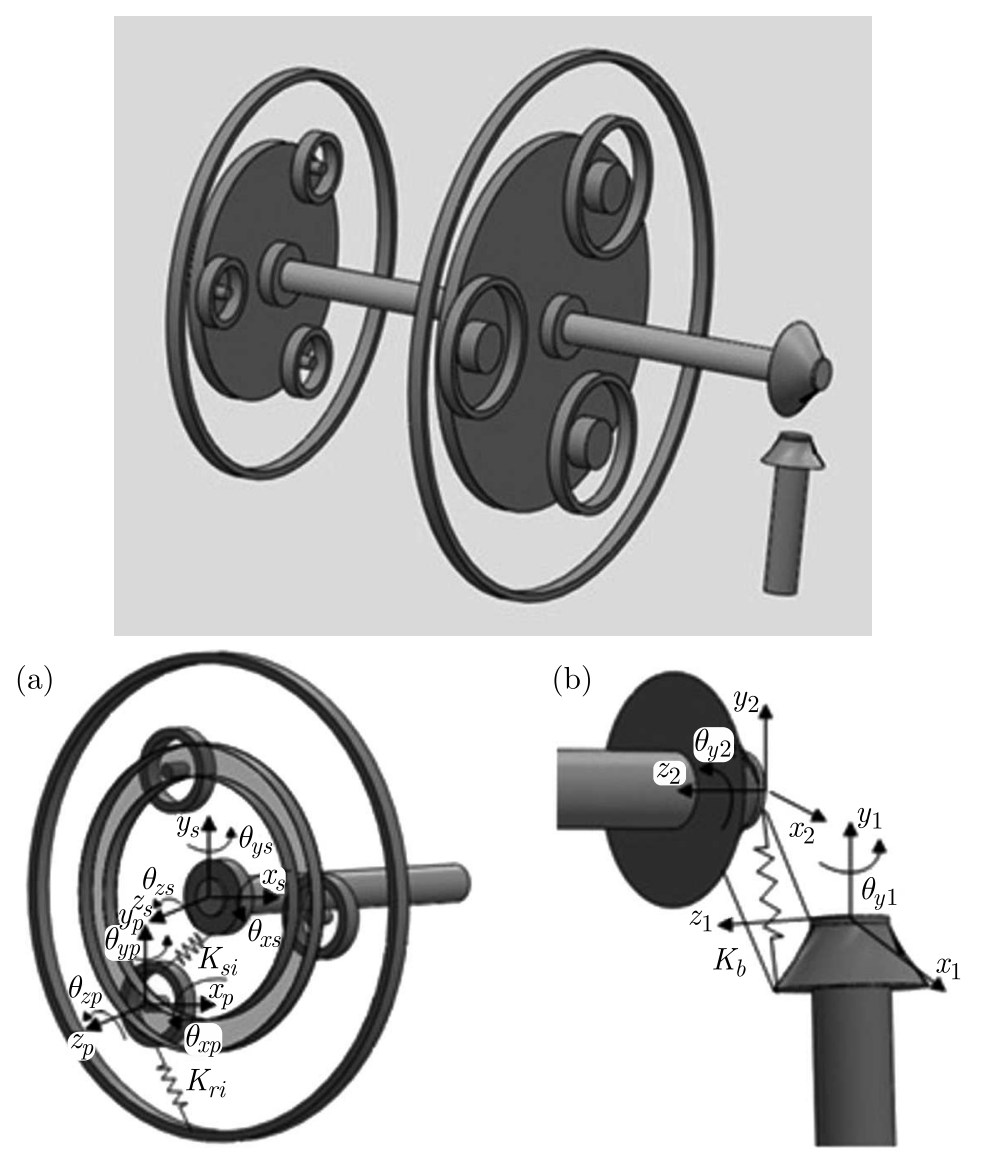

Fig. 3. Lumped parameter model: (a) planetary gear, (b) bevel gear

\subsection{Spiral bevel gear model}

The spiral BG model is divided into two rigid blocks (pinion with $Z_{1}$ teeth and wheel with $Z_{2}$ teeth). Each block has four degrees of freedom (three translations $x_{i}, y_{i}, z_{i}(i=1,2)$, one rotation $\theta_{1}$ for the pinion, $\theta_{2}$ for wheel and $\theta_{m}$ for the motor). The shafts are modeled with torsional stiffness. In order to simulate the meshing, linear mesh stiffness acting along the lines of action is considered following the procedure given by Karray et al. (2013). The vector defining different degrees of freedom is

$$
\mathbf{q}_{B G}=\left\{x_{1}, y_{1}, z_{1}, \theta_{m}, \theta_{1}, x_{2}, y_{2}, z_{2}, \theta_{2}\right\}^{\mathrm{T}}
$$

\subsection{Planetary gear model}

For both stages of the planetary gear, a three-dimensional model is adopted. Each stage is composed of the sun gear $s$, ring gear $r$, which are coupled to each other by 3 planets $P$ mounted on a carrier $c$. These elements are considered as rigid bodies. Linear springs acting on the lines of action are used to simulate the meshing stiffness (Kahraman, 1994a,c). Bearings are accounted for by linear springs. Each component has six degrees of freedom: three translations $u_{j i}, v_{j i}$ and $w_{j i}$ and three rotations $\varphi_{j i}, \psi_{j i}$ and $\theta_{j i}(j=c, r, s, 1, \ldots, n, i=1$ for the first stage and $i=2$ for the second one). These coordinates are measured with respect to a frame 
$\left(O_{i}, s_{1 i}, t_{1 i}, z_{1 i}\right)$ fixed to the carrier and rotating with a constant angular speed $\Omega_{c i}$. The rotations $\varphi_{j i}, \psi_{j i}$ and $\theta_{j i}$ are replaced by their corresponding translational gear mesh displacements as

$$
\rho_{j i x}=R b_{j i} \varphi_{j i} \quad \rho_{j i y}=R b_{j i} \psi_{j i} \quad \rho_{j i z}=R b_{j i} \theta_{j i} \quad \begin{aligned}
& j=c, r, s, 1, \ldots, n \\
& i=1,2
\end{aligned}
$$

where $R b_{j i}$ is the base circle radius for the sun, ring, planet, and the radius of the circle passing through planet centers for the carrier.

The system elasticity is accounted for by $6 n+18$ DOFs for each stage, and the planetary gear displacement vector $\mathbf{q}_{j P G i}$ of each element is defined as

$$
\mathbf{q}_{j P G i}=\left[u_{j i}, v_{j i}, w_{j i}, \rho_{j i x}, \rho_{j i y}, \rho_{j i z}\right]^{\mathrm{T}} \quad j=c, r, s, 1, \ldots, n \quad i=1,2
$$

\subsection{Global model}

The objective is to obtain a unique differential system combining the BG stage and both stages planetary gear coordinates. The principle of the coupling consists in using an additional torsional stiffness joining the rotational degree of freedom of the bevel gear wheel and the sun gear of the first stage planetary gear and adding a linear spring joining the axial degrees of freedom of the same wheel and sun. The same are used to couple the axial and rotational degree of freedom of the carrier of the first stage and the sun of the second one.

Introducing the following extended state variable vector composed of the bevel and two stages planetary gear displacements

$$
\mathbf{q}_{G}=\left\{\mathbf{q}_{B G}, \mathbf{q}_{P G 1}, \mathbf{q}_{P G 2}\right\}
$$

Applying Lagrange formulation for each element allows us to obtain the equations of motion of the $9+2(18+6 n)$ degrees of freedom of the global system

$$
\mathbf{M}_{G} \ddot{\mathbf{q}}_{G}+\mathbf{C}_{G} \dot{\mathbf{q}}_{G}+\left[\mathbf{K}_{p G}+\mathbf{K}_{e G}(t)\right] \mathbf{q}_{G}=\mathbf{F}_{G}(t)
$$

where $\mathbf{q}_{G}, \mathbf{M}_{G}, \mathbf{C}_{G}, \mathbf{K}_{p G}, \mathbf{K}_{e G}, \mathbf{F}_{G}$ are respectively the displacement vector, mass, damping, bearing, mesh stiffness matrices and the force vector for the global system.

\section{Modal analysis}

The characteristics of the bevel gear model are presented in Table 1 while the characteristics of the two stages planetary gear are presented in Table 2 . It has a fixed ring and three planets.

Table 1. Characteristics of the spiral bevel gear

\begin{tabular}{|l|c|c|}
\hline \multicolumn{1}{|c|}{ Parameters } & Pinion & Wheel \\
\hline \hline Number of teeth $Z$ & 27 & 62 \\
\hline Mass $[\mathrm{kg}]$ & 300 & 800 \\
\hline Moment of inertia $\left[\mathrm{kg} \cdot \mathrm{m}^{2}\right]$ & 18 & 72 \\
\hline Axial stiffness $k_{x 1}, k_{y 2}[\mathrm{~N} / \mathrm{m}]$ & $1 \cdot 10^{9}$ & $2.3 \cdot 10^{9}$ \\
\hline Lateral stiffness $k_{y 1}, k_{z 1}, k_{x 2}, k_{z 2}[\mathrm{~N} / \mathrm{m}]$ & $8.8 \cdot 10^{9}$ & $1.3 \cdot 10^{10}$ \\
\hline Torsional stiffness $k_{\theta 1}, k_{\theta 2}[\mathrm{Nm} / \mathrm{rad}]$ & $1.2 \cdot 10^{4}$ & $7.4 \cdot 10^{4}$ \\
\hline Pressure angle & \multicolumn{2}{|c|}{$\alpha=20^{\circ}$} \\
\hline Spiral angle & \multicolumn{2}{|c|}{$\beta=20^{\circ}$} \\
\hline
\end{tabular}


Table 2. Characteristics of the planetary gear model

\begin{tabular}{|l|c|c|c|c|}
\hline & Sun & Ring & Carrier & Planet \\
\hline \hline Teeth number & $Z_{s 1}=21$ & $Z_{r 1}=150$ & - & $Z_{p 1}=64$ \\
& $Z_{s 2}=27$ & $Z_{r 2}=90$ & - & $Z_{p 2}=31$ \\
\hline Mass [kg] & $M_{s 1}=270$ & $M_{r 1}=4500$ & $M_{c 1}=2600$ & $M_{p 1}=1200$ \\
& $M_{s 2}=446$ & $M_{r 2}=1960$ & $M_{c 2}=1300$ & $M_{p 2}=600$ \\
\hline$J / R_{b i}^{2}$ & $\left(J / R_{b i}^{2}\right)_{1}=200$ & $\left(J / R_{b i}^{2}\right)_{1}=740$ & $\left(J / R_{b i}^{2}\right)_{1}=990$ & $\left(J / R_{b i}^{2}\right)_{1}=592$ \\
& $\left(J / R_{b i}^{2}\right)_{2}=281$ & $\left(J / R_{b i}^{2}\right)_{2}=387$ & $\left(J / R_{b i}^{2}\right)_{2}=618$ & $\left(J / R_{b i}^{2}\right)_{2}=294$ \\
\hline$I / R_{b i}^{2}$ & $\left(I / R_{b i}^{2}\right)_{1}=100$ & $\left(I / R_{b i}^{2}\right)_{1}=370$ & $\left(I / R_{b i}^{2}\right)_{1}=495$ & $\left(I / R_{b i}^{2}\right)_{1}=296$ \\
& $\left(I R_{b i}^{2}\right)_{2}=140$ & $\left(I / R_{b i}^{2}\right)_{2}=193$ & $\left(I / R_{b i}^{2}\right)_{2}=310$ & $\left(I / R_{b i}^{2}\right)_{2}=147$ \\
\hline Gearmesh & $k_{s p 1}=2.28 \cdot 10^{8}, k_{r p 1}=2.6 \cdot 10^{8}$ \\
stiffness $[\mathrm{N} / \mathrm{m}]$ & $k_{s p 2}=2.2 \cdot 10^{8}, k_{r p 2}=2.3 \cdot 10^{8}$ \\
\hline Bearing stiffness & $k_{j x}=k_{j y}=10^{8}, k_{j z}=10^{9}, j=c, s$ \\
{$[\mathrm{~N} / \mathrm{m}]$} & $k_{r x}=k_{r y}=k_{r z}=10^{10}, k_{x x}=k_{y y}=10^{8}, k_{z z}=10^{9}$ \\
\hline Torsional & $k_{j \varphi}=k_{j \psi}=10^{9}, k_{j \theta}=0, j=c, s, 1, \ldots, n$ \\
stiffness [N/m] & $k_{r \varphi}=k_{r \psi}=k_{r \theta}=10^{10}$ \\
\hline Pressure angle & $\alpha=20^{\circ}$ \\
\hline Helix angle & $\beta=20^{\circ}$ \\
\hline
\end{tabular}

Table 3. Eigenfrequencies of the system

\begin{tabular}{|c|c|c|c|}
\hline \multicolumn{2}{|c|}{ Mode type } & $\begin{array}{l}\text { Multipli- } \\
\text { city }[\mathrm{m}]\end{array}$ & $\begin{array}{l}\text { Eigenfrequency } \\
{[\mathrm{Hz}]}\end{array}$ \\
\hline \multirow{3}{*}{$\begin{array}{l}\text { Bevel gear } \\
\text { mode }\end{array}$} & $\mathrm{C}$ & \multirow{3}{*}{1} & $f_{11}=56, f_{17}=64$ \\
\hline & $\mathrm{T}$ & & $f_{20}=67$ \\
\hline & $\mathrm{R}$ & & $f_{81}=1237$ \\
\hline \multirow[b]{2}{*}{$\begin{array}{l}\text { First } \\
\text { planetary } \\
\text { mode }\end{array}$} & $\mathrm{R}-\mathrm{A}$ & 1 & $\begin{array}{l}f_{4}=30, f_{35}=165, f_{44}=212, f_{49}=220 \\
f_{50}=246, f_{75}=649\end{array}$ \\
\hline & $\mathrm{T}-\mathrm{T}$ & 2 & $\begin{array}{l}f_{2,3}=20, f_{8,9}=38.7, f_{12,13}=58 \\
f_{18,19}=66, f_{24,25}=84.8, f_{36,37}=173 \\
f_{41,42}=204, f_{45,46}=213, f_{51,52}=251 \\
f_{56,57}=313, f_{73,74}=516, f_{77,78}=890\end{array}$ \\
\hline \multirow[b]{2}{*}{$\begin{array}{l}\text { Second } \\
\text { planetary } \\
\text { mode }\end{array}$} & $\mathrm{R}-\mathrm{A}$ & 1 & $\begin{array}{l}f_{23}=84.7, f_{59}=345, f_{60}=361 \\
f_{65}=420, f_{68}=442, f_{76}=838\end{array}$ \\
\hline & $\mathrm{T}-\mathrm{T}$ & 2 & $\begin{array}{l}f_{5,6}=38.5, f_{14,15}=63, f_{27,28}=100 \\
f_{31,32}=119, f_{33,34}=153, f_{47,48}=216 \\
f_{61,62}=364, f_{63,64}=416, f_{66,67}=434 \\
f_{69,70}=447, f_{71,72}=482, f_{79,80}=1147\end{array}$ \\
\hline \multicolumn{2}{|l|}{$\begin{array}{l}\text { Coupled } \\
\text { modes }\end{array}$} & 1 & $\begin{array}{l}f_{1}=0, f_{7}=38.6, f_{10}=46, f_{16}=63.7 \\
f_{21}=75, f_{22}=79, f_{26}=92, f_{29}=111 \\
f_{30}=117, f_{38}=179, f_{39}=199 \\
f_{40}=203, f_{43}=209, f_{53}=255 \\
f_{54}=275, f_{55}=300, f_{58}=341\end{array}$ \\
\hline
\end{tabular}

\subsection{Natural frequencies and vibration modes}

The undamped eigenvalue problem derived from the equation of motion by considering only the mean stiffness matrix $\overline{\mathbf{K}}$ is

$$
\left(-\omega_{i}^{2} \mathbf{M}_{G}+\overline{\mathbf{K}}_{G}\right) \phi_{i}=0
$$

where $\phi_{i}$ is the eigenvector and $\omega_{i}$ is the corresponding eigenfrequency. 
Natural frequencies and vibration modes of the system are given in Table 3. The natural modes are grouped according to the multiplicity of the natural frequencies. Several characteristics are revealed after a thorough comparison on the natural frequencies $\omega_{i}$ and modal vectors $\phi_{i}$.

- The first-order natural frequency is $\omega_{1}=0$, and the corresponding vibration mode is the rigid body mode. It is obvious that the rigid body mode can be eliminated by removing rigid-body motion.

- Bevel gear modes contain only modal deflection of BG components. They include four distinct natural frequencies:

- two natural frequencies with combined $(\mathrm{C})$ translational and rotational modal deflection. An example of this mode is observed in Fig. 4. The equilibrium positions are represented by a solid black line and the deflected positions are shown by a dashed black line. Similarly, Figs. 5-7 all abide by these rules;

- one natural frequency in which only rotation $(\mathrm{R})$ is observed;

- one in which only translation $(\mathrm{T})$ is observed.

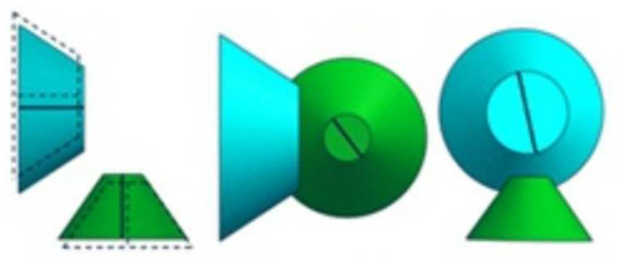

Bevel gear stage

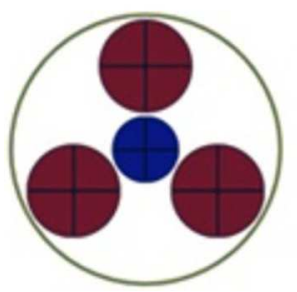

First stage planetary gear

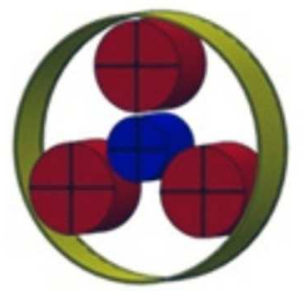

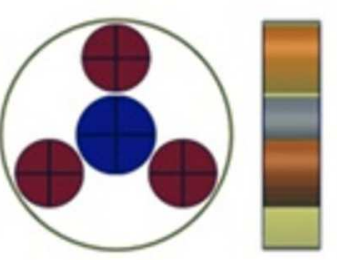

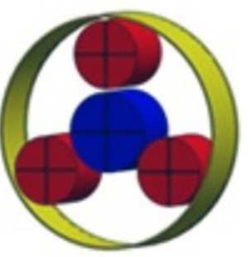

Second stage planetary gear

Fig. 4. Combined bevel gear mode at $f_{11}=56 \mathrm{~Hz}$

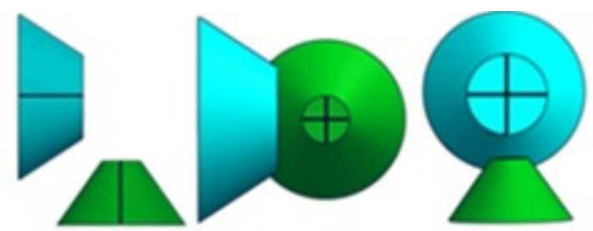

Bevel gear stage

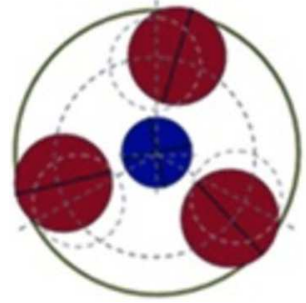

First stage planetary gear

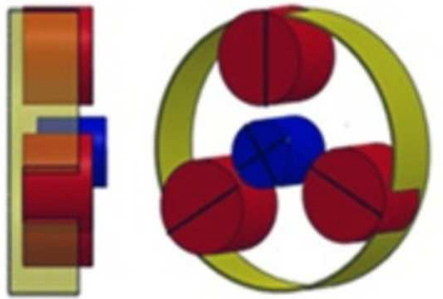

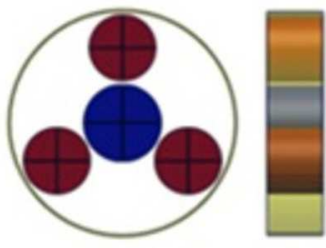

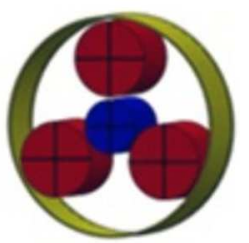

Second stage planetary gear

Fig. 5. Rotational-axial mode of the first stage planetary gear at $f_{4}=30 \mathrm{~Hz}$ 


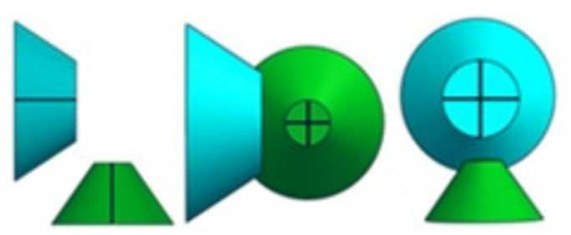

Bevel gear stage

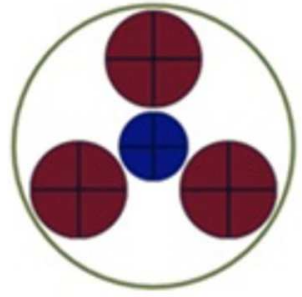

First stage planetary gear

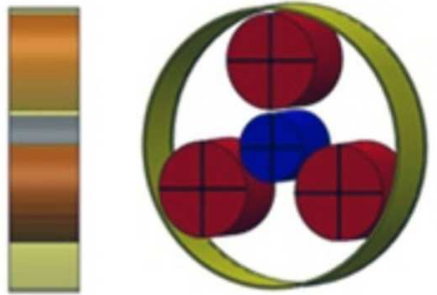

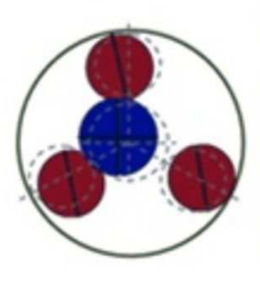
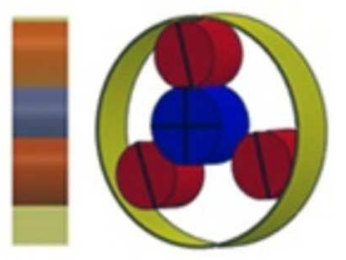

Second stage planetary gear

Fig. 6. Translational-tilting mode of the second stage planetary gear at $f_{5,6}=38.5 \mathrm{~Hz}$

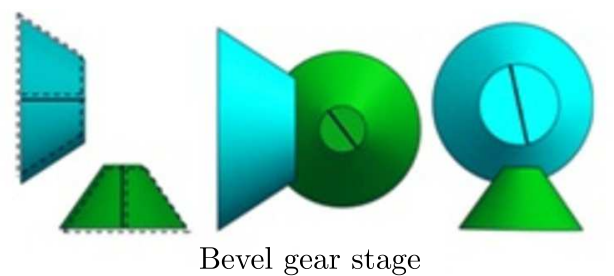

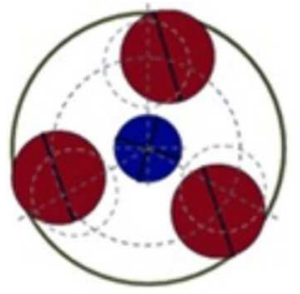

First stage planetary gear

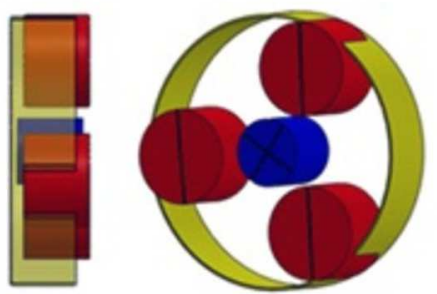

Fig. 7. Coupled mode at $f_{7}=38.6 \mathrm{~Hz}$
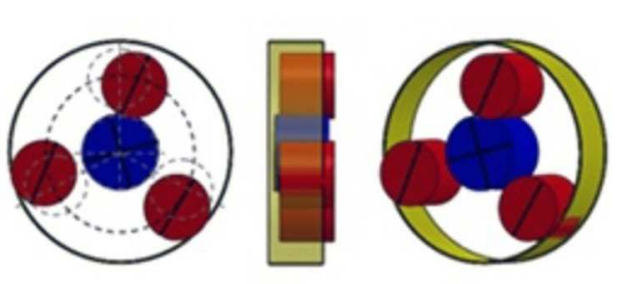

Second stage planetary gear - Planetary gear modes in which there are only modal deflection of the 2 stage planetary
gear components include:

- twelve natural frequencies with the multiplicity $m=1$. The related vibration modes are rotational-axial (R-A) modes in which the carriers, rings and suns rotate and translate axially, but they do not tilt or translate in-plane. The planets move identically and in phase. Figure 5 shows one rotational mode of the system;

- twenty four natural frequencies with the multiplicity $m=2$. The related vibration modes are translational-tilting (T-T) modes in which the carriers, rings and suns only translate in-plane and tilt but do not rotate or translate axially. In addition, the following relations between the deflections are noticed for each double mode: $u_{i 1}=v_{i 2}, v_{i 1}=u_{i 2}$ and $\varphi_{i 1}=\psi_{i 2}, \psi_{i 1}=-\varphi_{i 2}(i=c, r, s)$, where $u_{i 1}, v_{i 1}, \varphi_{i 1}, \psi_{i 1}$ are modal deflections in the first mode and $u_{i 2}, v_{i 2}, \varphi_{i 2}, \psi_{i 2}$ are modal deflections in the second mode;

- the planets exhibit sequentially phased motion. Figure 6 shows one rotational mode of the system; 
- the planet modes exist only if the number of planet $N>3$ and have the multiplicity $m=N-1$. In both stages of theplanetary gear, there are only three planets $(N=3)$. So, only the previous classes of modes appear when solving the eigenvalue problem.

- Modal properties of the two-stage planetary gears are analogous to those of simple, singlestage planetary gears. Features of rotational and translational modes are identical.

- The coupled mode which includes seventeen distinct natural frequencies includes movement of the different stages. Figure 7 illustrates the vibration modes of the system.

\subsection{Analysis of the distribution of modal kinetic strain energies}

Computation of the modal strain energy and the modal kinetic energy distributions gives information on bodies brought to critical speeds (which excite the natural frequencies) in terms of dominant motion and deformation.

The total modal strain energy can be written as the sum of strain energies of rotation and translation from each component of the system

$$
\begin{aligned}
E p_{\phi} & =\frac{1}{2} \boldsymbol{\phi}_{i}^{\mathrm{T}} \overline{\mathbf{K}} \phi_{i}=\sum E p_{\phi k}+\sum E p_{\phi k \omega}+E p_{\phi p w}+\sum E p_{\phi j i}+\sum E p_{\phi j i \omega} \\
& +\sum\left(E p_{\phi s i n}+E p_{\phi r i n}\right)
\end{aligned}
$$

where $E p_{\phi k}$ and $E p_{\phi k \omega}$ are the strain energies of the bearing stiffness in the rotational and translational motion of the pinion and wheel $(k=p, w)$, respectively. $E p_{\phi p w}$ is the strain energy of the pinion-wheel meshing. $E p_{\phi j i}$ and $E p_{\phi j i \omega}$ are the strain energies of the bearing stiffness in the rotational and translational motion of the carriers, suns, rings and planets $(j=c, r, s, 1,2,3)$ in both stages ( $i=1$ for the first stage and $i=2$ for the second stage). $E p_{\phi s i n}$ and $E p_{\phi r i n}$ are the strain energies of the sun $i$-planets and ring $i$-planets meshing in both stages.

The modal kinetic energy can also be written as the sum of the kinetic energies of rotation and translation from each component of the system

$$
E c_{\phi}=\frac{1}{2} \omega_{i}^{2} \phi_{i}^{\mathrm{T}} \mathbf{M} \phi_{i}=\sum E c_{\phi k}+\sum E c_{\phi k \omega}+\sum E c_{\phi j i}+\sum E c_{\phi j i \omega}
$$

where $E c_{\phi k}$ and $E c_{\phi k \omega}$ are the kinetic energies of the bearing stiffness in the rotational and translational motion of the pinion and wheel $(k=p, w) . E c_{\phi j i}$ and $E c_{\phi j i \omega}$ are the kinetic energies in the rotational and translational motion of the suns, carriers, rings and planets $(j=s, c, r, t, 1,2,3)$ in the first stage and the second one $(i=1,2)$.

Figure 8 shows the distribution of modal kinetic energies in low frequencies.

In the $X$-axis, the contribution of each degree of freedom in the total modal strain energy is represented. Details are given in Table 4.

Figure 9 shows the distribution of modal strain energies in low frequencies, where the $X$-axis is defined in Table 5 .

Table 6 presents a resume of the modal dominant motion and the dominant strain energy in each low-frequency mode.

Figure 10 shows the distribution of modal kinetic and strain energies in high frequencies. The $X$-axis is defined in Table 4 . 

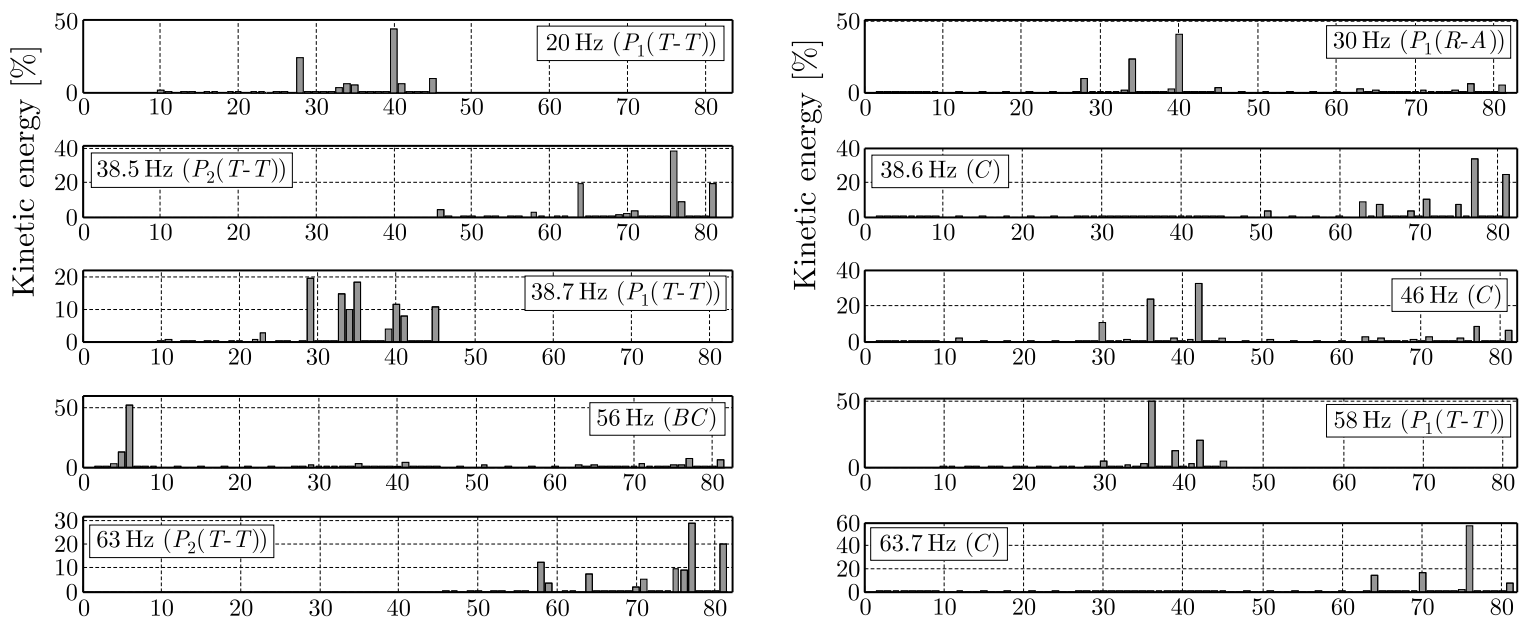

Fig. 8. Modal kinetic energies in low-frequencies

Table 4. The $X$-axis location of kinetic energies

\begin{tabular}{|c|l|c|l|}
\hline $1-3$ & Translation of pinion & $40-42$ & Translation of planet 3 of 1st stage \\
\hline 4 & Rotation of bearing motor & $43-45$ & Rotation of planet 3 of 1st stage \\
\hline 5 & Rotation of pinion & $46-48$ & Translation of carrier of 2nd stage \\
\hline $6-8$ & Translation of wheel & $49-51$ & Rotation of carrier of 2nd stage \\
\hline 9 & Rotation of wheel & $52-54$ & Translation of ring of 2nd stage \\
\hline $10-12$ & Translation of carrier of 1st stage & $55-57$ & Rotation of ring of 2nd stage \\
\hline $13-15$ & Rotation of carrier of 1st stage & $58-60$ & Translation of sun of 2nd stage \\
\hline $16-18$ & Translation of ring of 1st stage & $61-63$ & Rotation of sun of 2nd stage \\
\hline $19-21$ & Rotation of ring of 1st stage & $64-66$ & Translation of planet 1 of 2nd stage \\
\hline $22-24$ & Translation of sun of 1st stage & $67-69$ & Rotation of planet 1 of 2nd stage \\
\hline $25-27$ & Rotation of sun of 1st stage & $70-72$ & Translation of planet 2 of 2nd stage \\
\hline $28-30$ & Translation of planet 1 of 1st stage & $73-75$ & Rotation of planet 2 of 2nd stage \\
\hline $31-33$ & Rotation of planet 1 of 1st stage & $76-78$ & Translation of planet 3 of 2nd stage \\
\hline $34-36$ & Translation of planet 2 of 1st stage & $79-81$ & Rotation of planet 3 of 2nd stage \\
\hline $37-39$ & Rotation of planet 2 of 1st stage & & \multicolumn{2}{|l}{} \\
\hline
\end{tabular}
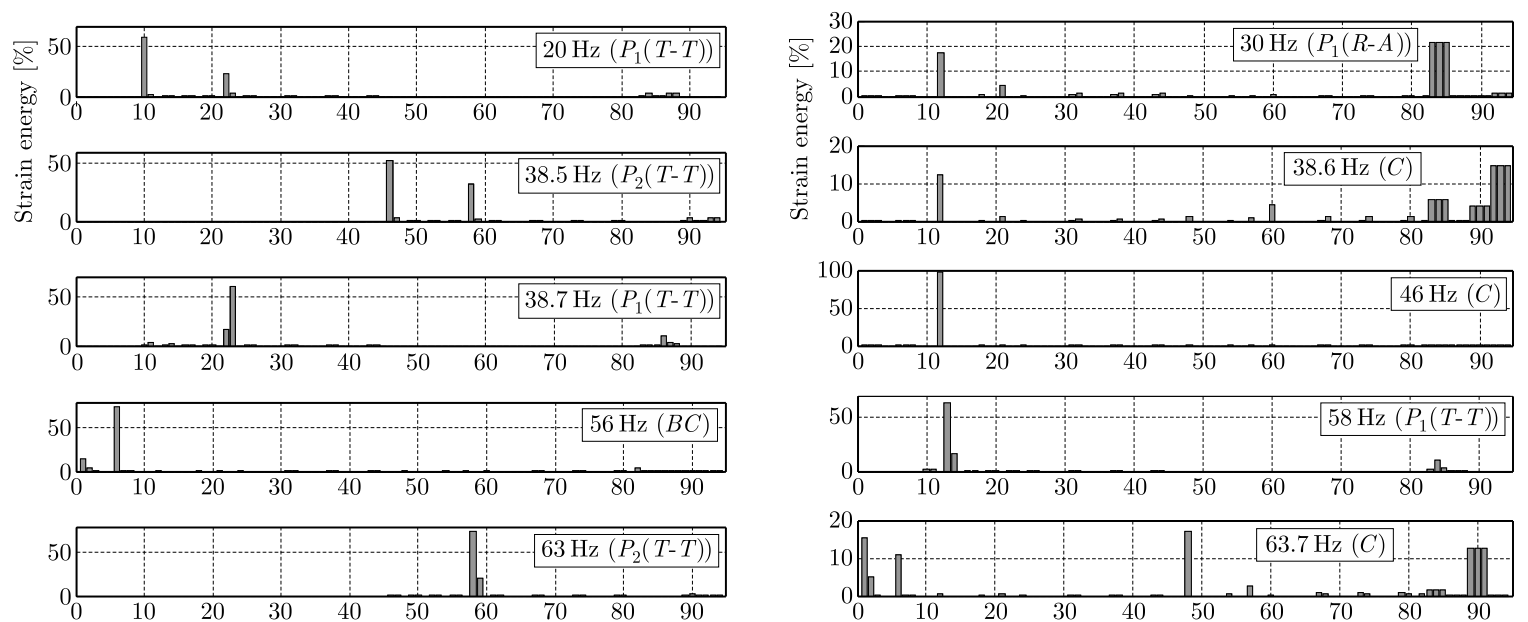

Fig. 9. Strain energy in low-frequencies 
Table 5. The X-axis location of strain energies

\begin{tabular}{|c|l|c|l|}
\hline $1-3,5$ & Bearing of pinion & $52-57$ & Bearing of ring of 2nd stage \\
\hline 4 & Bearing of motor & $58-63$ & Bearing of sun of 2nd stage \\
\hline $6-9$ & Bearing of wheel & $64-69$ & Bearing of planet 1 of 2nd stage \\
\hline $10-15$ & Bearing of carrier of 1st stage & $70-75$ & Bearing of planet 2 of 2nd stage \\
\hline $16-21$ & Bearing of ring of 1st stage & $76-81$ & Bearing of planet 3 of 2nd stage \\
\hline $22-27$ & Bearing of sun of 1st stage & 82 & Meshing pinion-wheel \\
\hline $28-33$ & Bearing of planet 1 of 1st stage & $83-85$ & Meshing ring-planets of 1st stage \\
\hline $34-39$ & Bearing of planet 2 of 1st stage & $86-88$ & Meshing sun-planets of 1st stage \\
\hline $40-45$ & Bearing of planet 3 of 1st stage & $89-91$ & Meshing ring-planets of 2nd stage \\
\hline $46-51$ & Bearing of carrier of 2nd stage & $92-94$ & Meshing sun-planets of 2nd stage \\
\hline
\end{tabular}

Table 6. Dominant motion and dominant strain energy in low-frequencies

\begin{tabular}{|c|c|l|l|}
\hline $\begin{array}{c}\text { No. of } \\
\text { mode }\end{array}$ & $\begin{array}{c}\text { Frequencies } \\
{[\mathrm{Hz}]}\end{array}$ & \multicolumn{1}{|c|}{ Modal dominant movement } & \multicolumn{1}{|c|}{ Dominant strain energy } \\
\hline \hline 2,3 & $20(\mathrm{~T}-\mathrm{T})$ & Transl. of planet 3 of 1st stage & Bearing of carrier of 1st stage \\
\hline 4 & $30(\mathrm{R}-\mathrm{A})$ & Transl. of planet 3 of 1st stage & Meshing sun-planets of 1st stage \\
\hline 5,6 & $38.5(\mathrm{~T}-\mathrm{T})$ & Transl. of planet 3 of 2nd stage & Bearing of carrier of 2nd stage \\
\hline 7 & $38.6(\mathrm{C})$ & Transl. of planet 3 of 2nd stage & Meshing ring-planets of 2nd stage \\
\hline 8,9 & $38.7(\mathrm{~T}-\mathrm{T})$ & Transl. of all planets of 1st stage & Bearing of sun of 1st stage \\
\hline 10 & $46(\mathrm{C})$ & Transl. of all planets of 1st stage & Bearing of carrier of 1st stage \\
\hline 11 & $56(\mathrm{~B})$ & Transl. of wheel & Bearing of wheel \\
\hline 12,13 & $58(\mathrm{~T}-\mathrm{T})$ & Transl. of planet 2 of 1st stage & Bearing of carrier of 1st stage \\
\hline 14,15 & $63(\mathrm{~T}-\mathrm{T})$ & Transl. of planet 3 of 2nd stage & Bearing of sun of 2nd stage \\
\hline 16 & $63.7(\mathrm{C})$ & Transl. of planet 3 of 2nd stage & $\begin{array}{l}\text { Bearing of carrier of 2nd stage } \\
\text { Meshing sun-planets of 2nd stage } \\
\text { Bearing of pinion }\end{array}$ \\
\hline & & & \multicolumn{2}{|l}{} \\
\hline
\end{tabular}
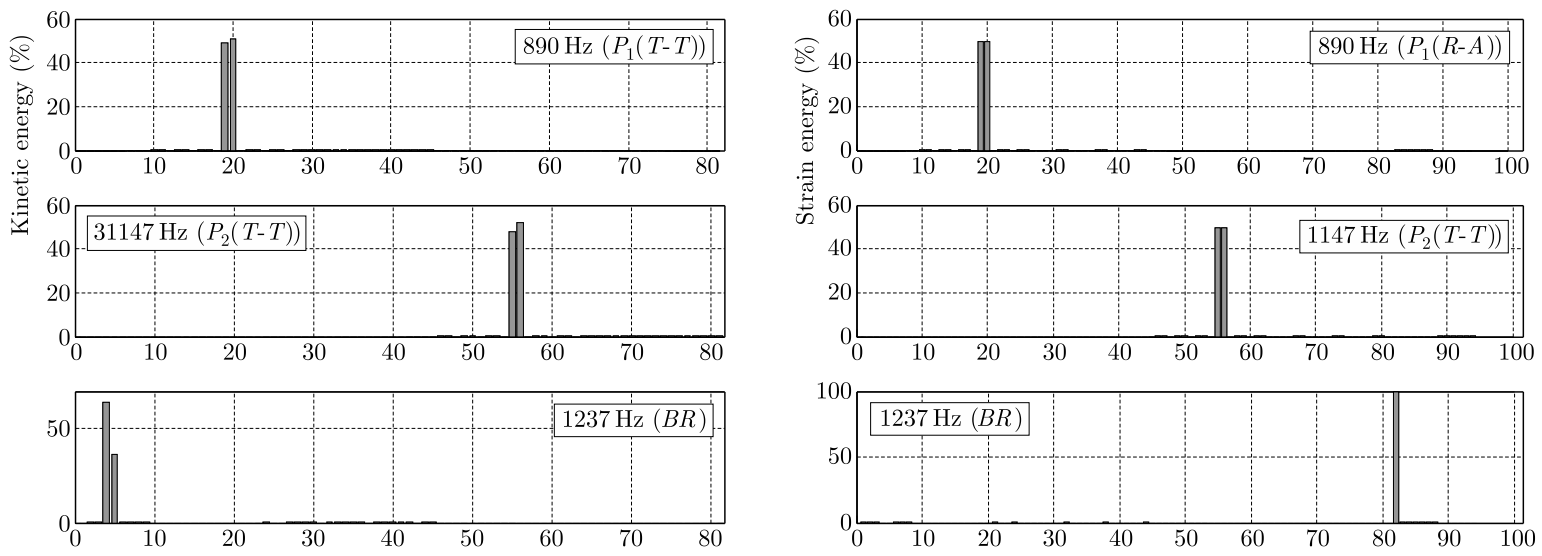

Fig. 10. Kinetic and strain energy in high-frequencies

Table 7 presents a resume of the modal dominant motion and the dominant strain energy in each high-frequency mode. 
Table 7. Dominant motion and dominant strain energy in high-frequencies

\begin{tabular}{|c|c|l|l|}
\hline $\begin{array}{c}\text { No. of } \\
\text { mode }\end{array}$ & $\begin{array}{c}\text { Frequencies } \\
{[\mathrm{Hz}]}\end{array}$ & \multicolumn{1}{|c|}{ Modal dominant movement } & \multicolumn{1}{|c|}{ Dominant strain energy } \\
\hline \hline 77,78 & $890(\mathrm{~T}-\mathrm{T})$ & Rotation of ring of 1st stage & Bearing of ring of 1st stage \\
\hline 79,80 & $1147(\mathrm{~T}-\mathrm{T})$ & Rotation of ring of 2nd stage & Bearing of ring of 2nd stage \\
\hline 81 & $1237(\mathrm{~B})$ & $\begin{array}{l}\text { Rotation of bearing motor } \\
\text { Meshing pinion-wheel }\end{array}$ & Rotation of pinion \\
\hline
\end{tabular}

\section{Conclusion}

This paper investigates modal properties of a special configuration of a gearbox composed of one stage spiral bevel gear coupled in a two stage helical planetary gear. A lumped-parameter model is formulated to obtain the equations of motion. The helical planetary gear system is represented by a three-dimensional lumped-parameter model with six degrees of freedom per gear and the shaft body supported by bearings. Solution of the eigenvalue problem allowed recovering modal characteristics of the transmission. It has been found that natural frequencies can be divided into three main mode classes: coupled modes, bevel gear modes and planetary gear modes. The last class of modes includes two types: the first one is a rotational-axial mode in which the central components rotate and move axially but do not tilt or translate with identical modal deflection of the planets; there are also 12 rotational-axial modes with distinct natural frequencies, the second one is a translational-tilting mode in which the central members tilt and translate in-plane but do not rotate or move axially; there are 12 pairs of degenerate translational-tilting modes with the natural frequency multiplicity two. When looking at the modal kinetic and strain energy distributions, another classification emerges according to the dominant energy in the system for each natural frequency.

\section{References}

1. Blankenship G.W., Singh R., 1995, A new gear mesh interface dynamic model to predict multidimensional force coupling and excitation, Mechanism and Machine Theory, 30, 1, 43-57

2. Choy K., Tu Y.K., Savage M., Townsend D.P., 1991, Vibration signature and modal analysis of multi-stage gear transmission, Journal of the Franklin Institute, 328, 2/3, 281-298

3. Eritenel T., Parker R.G., 2009, Modal properties of three-dimensional helical planetary gears, Journal of Sound and Vibration, 325, 397-420

4. Gosselin C., Cloutier L., NGuyen Q.D., 1995, A general formulation for the calculation of the load sharing and transmission error under load of spiral bevel and hypoid gears, Mechanism and Machine Theory, 30, 3, 433-450

5. Guo Y., Parker R.G., 2010, Sensitivity of general compound planetary gear natural frequencies and vibration modes to modal parameters, Journal of Vibration and Acoustics, 132, 1

6. Habib R., ChaAri F., Fakhfakh T., Haddar M., 2005, Three dimensional model for a helical planetary gear train vibration analysis, International Journal of Engineering Simulation, 6, 3, 32-38

7. Hammami A. Del Rincon A.F., Rueda F.V., Chaari F., Haddar M., 2015, Modal analysis of back-to-back planetary gear: experiments and correlation against lumped-parameter model, Journal of Theoretical and Applied Mechanics, 53, 1, 125-138

8. Kahraman A., 1994a, Dynamics of a multi-mesh helical gear train, ASME Journal of Mechanical Design, 116, 706-712

9. Kahraman A., 1994b, Natural modes of planetary gear trains, Journal of Sound and Vibration, 173, $125-130$ 
10. Kahraman A., 1994c, Planetary gear train dynamics, ASME Journal of Mechanical Design, 116, 713-720

11. Karray M., Chaari F., Viadero F., del Rincon A.F., Haddar M., 2013, Dynamic response of single stage bevel gear transmission in presence of local damage, The 4th European Conference on Mechanism Science, EUCOMES'2012, Spain, New Trends in Mechanism and Machine Science, Mechanisms and Machine Science, 7, 2013, 337-345

12. Lin J., PARker R.G., 1999a, Analytical characterization of the unique properties of planetary gear free vibration, Journal of Vibration and Acoustics, 121, 3, 316-321

13. Lin J., PARker R.G., 1999b, Sensitivity of planetary gear natural frequencies and vibration modes to model parameters, Journal of Sound and Vibration, 228, 1, 109-128

14. Lin J., PARKer R.G., 2000, Structured vibration characteristics of planetary gears with unequally spaced planets, Journal of Sound and Vibration, 233, 5, 921-928

15. Lin J., PARker R.G., 2004, Mesh phasing relationships in planetary and epicyclic gears, Journal of Mechanical Design, 126, 365-370

16. Ozguven H.N., Houser D.R., 1988a, Dynamic analysis of high speed gears by using loaded static transmission error, Journal of Sound and Vibration, 125, 71-83

17. Ozguven H.N., Houser D.R., 1988b, Mathematical models used in gear dynamics - a review, Journal of Sound and Vibration, 121, 383-411

18. Rusinski E., Harnatkiewicz P., Kowalczyk M., Moczko P., 2010, Examination of the causes of a bucket wheel fracture in a bucket wheel excavator, Engineering Failure Analysis, 17, 1300-1312

19. SEager D.L., 1975, Conditions for the neutralization of excitation by the teeth in epicyclic gearing, Journal of Mechanical Engineering Science, 17, 5, 293-298

20. Sun W., Ding X., Wei J., Hu X., Wang Q., 2014, An analyzing method of coupled modes in multi-stage planetary gear system, International Journal of Precision Engineering and Manufacturing, 15, 11, 2357-2366

21. Velex P., MaAtar M., 1996, A mathematical model for analyzing the influence of shape deviations and mounting errors on gear dynamic behaviour, Journal of Sound and Vibration, 191, 629-660

22. Wu X., PARker R.G., 2008, Modal properties of planetary gears with an elastic continuum ring gear, Journal of Applied Mechanics, 75, 3, 1-10

23. Zhang L., Wang Y., Wu K., Sheng R., Huang Q., 2016, Dynamic modeling and vibration characteristics of a two-stage closed-form planetary gear train, Mechanism and Machine Theory, 97, 12-28 